\title{
ASSESORIA DE COMUNICAÇÃO PARA PROFISSIONAIS LIBERAIS: UMA VISÃO DO MERCADO GOIANENSE
}

\author{
COMMUNICATION OFFICE BY PROFESSIONALS: A GOIÂNIA MARKET VISION
}

\section{ASESOR DE COMUNICACIÓN PARA PROFESIONAL LIBERAL: UNA VISIÓN DEL MERCADO GOIANENSE}

\author{
Claudomilson Fernandes Braga ${ }^{1}$ \\ Doutorando em Psicologia \\ Professor Assistente da Faculdade de Comunicação e Biblioteconomia \\ Universidade Federal de Goiás. milsonprof@gmail.com \\ Simone Antoniaci Tuzzo ${ }^{2}$ \\ Doutora em Comunicação \\ Professora Efetiva do Programa de Pós-Graduação em Comunicação \\ Universidade Federal de Goiás. simonetuzzo@ hotmail.com
}

\section{RESUMO}

Este artigo objetiva identificar o grau de consciência dos profissionais liberais quanto à necessidade de uma Assessoria de Comunicação que trabalhe a formação de imagem e identidade diante de uma sociedade cada vez mais competitiva. A pesquisa realizada com profissionais das mais variadas áreas de atuação na Cidade de Goiânia aponta o desconhecimento por parte desses profissionais sobre a possibilidade de uma atuação de outros profissionais que agregue valor às suas atuações profissionais, preferindo, na maioria das vezes, atuarem de forma independente. Ao mesmo tempo abre uma importante discussão sobre a atuação dos Assessores de Comunicação nesse campo que transcende as organizações de pequeno, médio e grande porte e apresenta os Profissionais Liberais como gestores de seus próprios negócios, com necessidades de atuação de profissionais da comunicação. A visão de que os profissionais de comunicação também são gestores de seus próprios negócios também é relevante para esta pesquisa.

Palavras chave: Profissionais Liberais. Assessoria de Comunicação. Imagem.

\section{ABSTRACT}

This article aims to identify the degree of awareness of professionals on the need for communication departments to work the formation of image and identity in the face of an increasingly competitive society. The survey of professionals from many areas in the city of Goiania shows their ignorance of the value other professionals will add to their professional performances, rather they prefer in most cases to act independently. The important role of advisors in the field of communication transcends all organizations (small, medium and large). As a result, handymen, as the managers of their own businesses, need communication professionals for their performance.

Key words: Handyman. Communication office. Image. 


\section{RESUMEN}

Este artículo tiene como objetivo identificar el grado de conciencia de los profesionales sobre la necesidad de un asesor de comunicaciones para trabajar la formación de la imagen y la identidad en la cara de una sociedad cada vez más competitivo. La encuesta de profesionales de distintas áreas de negocio en la ciudad de Goiania muestra la ignorancia por parte de los profesionales sobre la posibilidad de una participación de otros profesionales que agreguen valor a su desempeño profesional, prefiriendo en su mayoría de forma independiente. Al mismo tiempo se abre un importante debate sobre el papel de los asesores en el campo de la comunicación que trasciende las organizaciones pequeñas, medianas y grandes, y muestra a los profesionales como los gestores de su propio negocio con las necesidades de rendimiento de los profesionales de la comunicación. La idea de que los profesionales de la comunicación son también responsables de su propio negocio también es relevante para esta investigación.

Palavras clave: Profesional liberal. Oficina de Comunicación. Imagen

\section{INTRODUÇÃO}

O profissional liberal tem, como diferencial competitivo, a sua credibilidade, sua marca, sua imagem. Ocorre que, durante o curso de graduação e pós-graduação, por motivos diversos e também por uma confusão conceitual que leva a interpretar a assessoria de comunicação somente como propaganda ou assessoria de imprensa, os profissionais liberais são desestimulados a valorizar esse trabalho, confiando no antigo "boca-a-boca" como forma de difusão de seu valor.

Profissionais da área médica, por exemplo, que veem suas carreiras seguirem paralelas à consolidação dos intermediários - planos de saúde, por exemplo - na relação médicopaciente, são colocados numa espécie de commodity que o intermediário oferece aos seus consumidores, nivelando tanto os bons profissionais, como aqueles que não mereceriam tal definição.

$\mathrm{Na}$ verdade essa não é uma característica somente da área médica, mas de profissionais como advogados, cabeleireiros, arquitetos ou os demais que atuam de forma a manter uma imagem positiva sobre o seu nome.

Além disso, o trabalho dos Assessores de Comunicação que comumente se desenvolve com organizações de pequeno, médio e grande porte das mais variadas áreas de produtos e serviços também é ampliado e os profissionais de comunicação se veem na perspectiva de atuarem também como profissionais liberais, com pessoas que passam a gerir o seu próprio negócio no trato diário com clientes e pacientes e não necessariamente como empresa constituída. 
Nesse sentido, o profissional de Relações Públicas parece agregar uma gama de conhecimentos teórico e prático, que possibilita atuar como assessor de comunicação para profissionais liberais. O que, segundo a Confederação Interamericana de Relações Públicas (CONFIARP), são as relações públicas que melhor desempenham esse papel: o assessor de comunicação.

Neste estudo, foram entrevistados 26 profissionais liberais das áreas de música, design, direito, fisioterapia, odontologia, eventos e vendas a fim de termos a visão sobre comunicação daqueles que atuam como gestores de seus próprios negócios e na construção de um nome como a sua própria marca.

\section{IMAGEM E IDENTIDADE}

A Assessoria de Comunicação pode atuar como fator de reforço ou correção da imagem na consecução dos objetivos pretendidos por uma organização social nos mais variados níveis: municipal, estadual, federal e ainda organizações privadas. Além disso, pode atuar na formação de imagem de profissionais liberais. O processo não é novo e a sociedade aprendeu a conviver com assessores de celebridades, aqui compreendido como aqueles profissionais cujo reconhecimento do mercado de atuação os tornam célebres, reconhecidos e até referenciados, nomeadamente das áreas esportiva ou artística. Contudo, depara-se ainda com certas restrições para atuação na carreira dos profissionais liberais de todas as áreas que parecem imaginar ser suficiente desenvolver um trabalho solo, sem ajuda de profissionais de outras áreas de conhecimento, como a comunicação, por exemplo.

Como ponto de partida, e se apropriando dos conceitos de marketing sobre marca ou branding, devemos traçar duas visões distintas: uma interna que diz respeito a identidade e outra externa que se refere a imagem. Segundo Bender (2009, p.171), na visão interna teremos a identidade de marca, na visão externa, a imagem de marca.

\footnotetext{
A primeira, a identidade, é o conceito que traçamos para uma marca, um DNA de marca planejado. São os valores e atributos que queremos passar para o mercado. A segunda, a imagem da marca, é a percepção, a maneira como a marca é percebida pela audiência. $\mathrm{O}$ que se faz num planejamento estratégico é, por meio do marketing e da comunicação, aproximar essas duas visões, diminuindo a dissonância cognitiva entre elas. É levar os consumidores a perceberem a marca com o valor que queremos que ela tenha. (BENDER, 2009, p.171)
}

O que fazer e não fazer pela imagem de uma organização ou de um profissional liberal são questões que envolvem o dia-a-dia dos profissionais de comunicação, profissionais que buscam incessantemente colocar as organizações públicas ou privadas que representam num 
conceito elevado junto à opinião pública, ou junto aos públicos de interesse da organização ou da pessoa física que assessoram.

Por ter como uma das suas principais funções a gestão da imagem pública, os profissionais de comunicação utilizam-se da pesquisa para obtenção de uma visão ampla da realidade em que atuam, e com isso, tomam as decisões mais apropriadas com a intenção de atingir o desejo maior de toda administração: conquistar a boa vontade dos públicos prioritários e de interesse. Assim, além de segui-las e respeitá-las, serem agentes multiplicadores fiéis e indispensáveis ao seu crescimento e ao seu sucesso.

Dessa forma, a principal função dos assessores de comunicação passa pela construção e manutenção da imagem institucional/pessoal, e esta transcende a dimensão operacional da publicidade, cuja vocação é divulgar produtos, organizações e dialogar com o mercado com o intuito de propiciar e alavancar o consumo. Essa transcendência alcança uma dimensão estratégica, de pensar logicamente na sistematização de conhecimento na área da comunicação, no âmbito das relações humanas e na utilização de instrumentos adequados na criação da imagem e seu monitoramento.

\section{CONSTRUÇÃO DA OPINIÃO DOS PÚBLICOS}

É importante fazer a separação das interfaces do assessorado (seja ele pessoa física ou pessoa jurídica) com os seus públicos e com a opinião pública. Os públicos pertencem ao relacionamento contínuo e necessário do assessorado, garantindo-lhe a sobrevivência e o apoio às suas atividades e contribuindo para criar um conceito favorável junto à opinião pública. Eles existem independentemente da vontade da empresa ou do profissional liberal.

Apresentaremos aqui uma definição focada na assessoria empresarial, tendo em vista a restrita bibliografia ainda existente sobre a atuação das assessorias de comunicação para profissionais liberais, contudo, a forma de atuação pode ser trabalhada dentro dos mesmos princípios teóricos:

Os relacionamentos da empresa com seus públicos estratégicos centralizam-se nos níveis de sua participação social como sustentadores da empresa, parceiros em negócios, consumidores, e, o que não é menos importante, como formadores da opinião pública, atentos à projeção do conceito da empresa junto a ela e aos líderes de opinião. (FRANÇA, 2004, p. 122)

Já a opinião pública:

É o resultado de opiniões individuais sobre os assuntos de interesse comum que se origina nas diferentes formas de comunicação humana, primeiramente através de 
processos individuais, posteriormente, em processos coletivos, em diferentes graus, segundo a natureza das informações compartilhadas pelos indivíduos, às vezes influenciada pelos interesses particulares de grupos afetados. (PRADA, apud TUZZO, 2005, p. 35)

Enquanto questão da Comunicação Social, a formação da opinião pública está ligada ao poder de retórica que o conteúdo do processo de comunicação tem de gerar uma resposta à mensagem, que por sua vez gera uma opinião, que provoca outra reação que gerará outra opinião, numa cadeia de estímulo e efeito da comunicação. Assim, a primeira etapa da formação da opinião é a comunicação total, pessoal, direta e recíproca. (PRADA, 1995).

Para Guareschi (1991), numa sociedade onde a comunicação é capaz de construir ou alterar a realidade dos fatos, quem detém o domínio dessa comunicação detém o poder sobre a existência das coisas, a difusão das idéias e a criação da opinião pública. "Quem tem a palavra constrói identidades pessoais ou sociais" (GUARESCHI, 1991, p. 14-15).

Devemos considerar também as variáveis que compõem o receptor dessas mensagens. Cada indivíduo é composto por três elementos estruturais: cultura, sociedade e personalidade. São relevantes também a consciência, os fatores psicológicos e as experiências. O real é a realidade de cada receptor a partir das suas possibilidades de interpretação. Sendo assim, expressar uma opinião é uma necessidade de interação no meio social em que está inserido. (TUZZO, 2005)

\footnotetext{
Resgatando as idéias de Bourdieu, na composição da opinião pública nem todos possuem opiniões formadas sobre todos os acontecimentos sociais, tampouco necessariamente têm algo a dizer sobre um determinado tema proposto. Além disso, nem todas as opiniões emitidas se equivalem na composição da opinião pública porque essa se caracteriza, principalmente, pela existência de líderes de opinião e formas de indivíduos expressarem sua opinião publicamente, fazendo com que essas se sobreponham à opinião daqueles que não têm condições de expressar suas visões sobre fatos e acontecimentos. (TUZZO, 2005, p. 58-59)
}

Analisando melhor os formadores da opinião pública, podemos dizer que se constituem daqueles que podem exercer influência sobre aquilo que uma pessoa ou um determinado grupo de pessoas pensa, deva pensar ou consumir. Podem ser membros da família, artistas, professores, líderes religiosos, atletas, socialites, líderes de classe, líderes sindicais, cientistas, pessoas famosas, celebridades midiáticas, pessoas públicas. Enfim, são pessoas que possuem o reconhecimento e o prestígio da sociedade.

A Confederação Interamericana de Relações Públicas (CONFIARP), criada em 1985, considera a ligação das relações públicas com a opinião pública, da seguinte forma: 
As relações públicas desenvolvem atividades sócio-técnico-administrativas, mediante a qual se pesquisa e avalia a opinião pública e se empreende um programa de ação planificado, contínuo e de comunicação recíproca, baseado no interesse da comunidade e destinado a manter uma afinidade e compreensão da mesma para com entidades de qualquer natureza. (ANDRADE, 1996, p. 105)

Quando atribuída especificamente à causa da opinião pública, Andrade (1996, p. 104) nos lembra de que "relações públicas são os métodos de integrar na opinião pública conceitos favoráveis relativos a uma pessoa ou instituição".

Assim, não é novidade que os profissionais de Relações Públicas e de outras especializações em Comunicação Social se caracterizam como importantes auxiliares na formação da opinião que determinados grupos de pessoas ou líderes de opinião poderão ter de uma empresa ou de um profissional que administra o seu próprio negócio.

Muitas vezes o público a ser atingido por um profissional que precisa oferecer os seus serviços para uma sociedade não consegue ser atingido somente pelos canais constituídos de comunicação, ou seja, a mídia de massa como rádio, jornal impresso, televisão, entre outros, porque esse público precisa de um tipo de comunicação dirigido e não comunicação de massa.

A harmonia entre a escolha do público, a adequação da linguagem e a escolha do veículo de difusão são fundamentais para o sucesso ou o fracasso de uma comunicação, e, na hipótese de um desses três itens não estarem em consonância com o objetivo de desenvolver e sustentar a imagem positiva do profissional liberal, a mensagem não surtirá o efeito esperado.

Importante destacar que, no caso dos profissionais liberais, nem sempre a necessidade é de divulgação para conquista de novos clientes, por exemplo, o que, em tese, poderia ser conquistado utilizando-se outras técnicas, tais como propagandas televisivas, mídias de exposição (outdoor). Muitas vezes a necessidade de um profissional é de alteração da carteira de clientes ou a ascensão de classe social de pacientes, conquistas que não dependem somente de publicidade, mas sim de estudo aprofundado de público e de adequação de mensagens.

\section{AMOSTRA, MÉTODO E PROCEDIMENTO}

A pesquisa realizada entre os meses de outubro a dezembro de 2010 caracteriza-se como qualitativa do tipo exploratória. Em virtude do grande volume da população-alvo, o processo amostral delimitou-se ao setor Marista, cuja população identificada foi de 198 profissionais liberais atuando no setor. A amostra classificada como aleatória simples 
(MALHOTRA, 2006), foi composta de 26 profissionais liberais das mais variadas áreas de atuação, compreendendo dessa forma um percentual de $13 \%$ da população.

O instrumento de coleta utilizado foi um questionário de entrevistas semi-estruturado com 28 questões abertas cujo objetivo era identificar num primeiro momento o perfil do profissional liberal que atua na cidade de Goiânia e num segundo momento qual a importância que esse profissional atribui a assessoria de comunicação como uma ferramenta de melhoria do seu desempenho profissional no mercado de atuação e ainda se esse profissional tinha conhecimento das atribuições de um assessor de comunicação.

A coleta ocorreu de forma pessoal, de modo que os sujeitos da pesquisa foram previamente contatados e em razão de um prévio agendamento, procedeu-se a coleta das informações. Para tanto, utilizou-se gravador para registro das informações, que posteriormente foram transcritas e interpretadas.

A interpretação dos dados coletados foi desenvolvida segundo a metodologia da codificação teórica (STRAUSS, 1987; STRAUSS e CORBIN, 1990/1998), que visa à ancoragem de dados para abastecer e definir a construção interpretativa de uma teoria de forma integrada. Composta por três fases, a codificação teórica compreende: a codificação aberta, onde o autor apresenta perguntas básicas: o quê? Quem? Como? Quando? Por quê? Por meio do quê? Cujas respostas possibilitam ordenar as informações através da técnica flipflop e embasar o passo seguinte da codificação; a codificação axial que trata do aprimoramento das categorias resultantes da codificação aberta, possibilitando um ajuntamento das categorias identificadas e a terceira fase - codificação seletiva - que permite um nível elevado de abstração e a possibilidade do agrupamento das categorias em famílias de codificação, ou seja, nesta fase os conteúdos já podem ser interpretados dando subsídios à construção de uma nova teoria ou a corroboração de uma teoria em construção.

Com o auxílio do software Atlas ti, a interpretação dos dados permitiu a interface com o software Statistical Package for the Social Sciences (SPSS), possibilitando uma leitura quantitativa dos dados, apesar da pesquisa se caracterizar como qualitativa.

\section{RESULTADOS E DISCUSSÃO}

Os resultados obtidos indicam duas grandes categorias de profissionais liberais atuantes no mercado: a primeira composta por aqueles que na tentativa de melhorar o seu rendimento opta $^{3}$ por desenvolver atividades no mercado abrindo mão do vínculo 
empregatício. São características as atividades de vendas, eventos e prestação de serviços não especializados, tais como organização de festas, formaturas, música; e outra categoria de profissionais especializados com formação superior - odontologia, advocacia, fisioterapia, medicina, design, dentre outras.

Essa categorização também indica uma diferença substancial de rendimentos. Os primeiros obtêm, em média, um rendimento que não ultrapassa dois salários mínimos nacionais, já na segunda categoria, os rendimentos são variados, ultrapassando quatro salários mínimos, podendo chegar a valores superiores a 10 salários.

Essa categorização também revela que os profissionais liberais sem qualificação optam sempre por terem o seu próprio negócio (escritório, oficina, atelier etc) na própria residência, talvez justificado pelo rendimento mediano, o que impossibilitaria a aquisição ou montagem de uma estrutura dedicada para esse fim. Já os profissionais com formação superior normalmente possuem uma estrutura formal e muitas vezes atuam em diversos locais durante o período diurno. Em alguns casos sendo proprietários, em outros alocando espaços dedicados a sua área de atuação.

Outro dado importante revelado pela pesquisa é o fato de que mesmo que os profissionais trabalhem com outros profissionais da mesma área de atuação (ou não), todos afirmam que são livres e não possuem nenhum tipo de vinculação societal, ou seja, o que parece caracterizar a atuação do profissional liberal é a carreira solo mesmo que juntamente com outros profissionais.

Quando questionados sobre a importância do profissional de comunicação (assessor) para melhorar sua performance no mercado, a maioria (89\%) não consegue atribuir uma importância nesse sentido. Alguns pelo desconhecimento das atividades de um assessor de comunicação (72\%), outros pela atribuição de menos importância, argumentando que não vê como um assessor poderia ajudar no seu desempenho.

Dos entrevistados, apenas uma pequena parte (11\%) atribui uma importância relativa à existência de um assessor de comunicação como parceiro na melhoria da sua imagem e por conseqüência do seu desempenho, sugerindo que prevalece a ideia da "carreira solo", ou seja, ser profissional liberal é atuar só, sem assessores, sem sócios.

Esses resultados indicam algumas possibilidades interpretativas sugerindo que as atividades do assessor de comunicação parecem ter uma relevância parcial na melhoria do desempenho profissional dos entrevistados. Essa relevância é explicada pelo desconhecimento das atividades desenvolvidas por esse profissional, mas, sobretudo, pelo perfil que caracteriza o profissional liberal no mercado: carreira solo, cuja hipótese parte da ideia trabalhada na 
construção do conhecimento profissional na educação formal, ou seja, nas faculdades e nas universidades.

Não há uma percepção relevante de que o assessor de comunicação é um aliado na melhoria da imagem da marca desse profissional e que muitas vezes esse assessor é, na verdade, um colaborador na construção dessa imagem positiva que pode alterar substancialmente o desempenho desse profissional no mercado diante da concorrência.

Os profissionais não percebem que a imagem de marca de um produto extrapola os limites desse conceito, ou seja, que a escolha de um profissional pode estar associada a boa imagem que ele desfruta no mercado, já que ele é a própria marca e, portanto, a sua imagem reflete diretamente no seu desempenho e na sua capacidade de melhorar a sua atuação no mercado. Para esses profissionais a dinâmica de construção de imagem é simples, ou seja, se fazem um bom trabalho o nome se consolida, se fazem um mau trabalho serão colocados à margem da "glória".

Também não fica claro para nenhum dos profissionais a ideia de que o assessor é um aliado e não um sócio ou um concorrente, justificando de certo modo o pouco interesse pela atividade de assessoramento e justificando a pouca importância atribuída a essa possibilidade.

Contudo, quando questionados sobre o futuro em suas carreiras, as falas remetem a uma ascensão profissional, financeira e o desejo de se tornarem mais famosos, mais conhecidos e consequentemente mais ricos.

Os profissionais liberais têm percepção da possibilidade de celebrização de seu nome e de se tornarem referência na área em que atuam, citando facilmente nomes de pessoas que se tornaram destaques como médicos, dentistas ou advogados e definem esses profissionais como competentes e pessoas de sorte, mas não têm noção de como fazer e o que fazer para que eles também caminhem numa direção que os conduzam a se tornarem celebridades em suas profissões.

Para a maioria dos entrevistados $(78 \%)$, ser famoso e poder se tornar uma celebridade é sempre algo que perpassa pelos meios de comunicação de massa e estar na mídia é a única condição de se tornar conhecido.

A grande maioria (85\%) também atribui a idéia de celebridade, somente àqueles que estão presentes nos veículos de comunicação, desconsiderando os seus públicos de interesse e os vários públicos aos quais pertencem como entidades de classe e associações, por exemplo.

Para a maioria dos entrevistados $(85 \%)$ a celebrização de um profissional liberal pode ser real para profissionais do esporte, por exemplo, mas para profissões como as deles isso é algo difícil e acima de tudo de busca desconhecida sobre como iniciar esse trabalho. 


\section{CONSIDERAÇÕES FINAIS}

A construção de marca e imagem é algo que a maioria dos profissionais liberais não imagina para si. O conceito de imagem e identidade organizacional trabalhado durante anos na sociedade faz com que este conceito ainda seja um processo em construção para a maioria dos profissionais liberais, contudo, na sociedade contemporânea as marcas de profissionais são determinantes para o destaque e até a sobrevivência desses profissionais.

$\mathrm{O}$ fato dos profissionais liberais encontrarem dificuldade no processo de conquista do mercado, está associado a ideia de que apenas as empresas necessitam de assessores de comunicação, e que essa possibilidade não é possível para os profissionais liberais, dificultando o trabalho em conjunto e colocando os profissionais em uma posição inferior na conquista de espaços no mercado.

O despertar desse trabalho que não é novo, e que já provou sua eficácia em profissionais como esportistas e artistas, por exemplo, é um processo em construção e, como todo avanço fará com que muitos tenham a tendência a acompanhá-lo, outros fiquem para trás, acompanhando os resultados sem a devida participação.

O exemplo de Goiânia parece refletir uma realidade de outros estados brasileiros que abrigam profissionais liberais e que ainda precisam aprender a dinâmica dos novos rumos sociais e profissionais e cabe aos próprios profissionais da comunicação apresentarem-se como sujeitos desse processo.

Assim como os profissionais liberais necessitam de um assessoramento, também os profissionais de comunicação que desenvolvem a função de Assessores de Comunicação e que optam por essa modalidade de atuação profissional, parecem também carecer desse autoassessoramento e auto-estudo, precisando, a princípio, serem comunicadores de si mesmos. Capazes de gerir a comunicação e a construção de uma imagem e de uma identidade próprias, para depois serem capazes de trabalhar a construção de imagem e identidade do outro.

\section{REFERÊNCIAS}

ANDRADE, Cândido Teobaldo de Souza. Dicionário Profissional de Relações Públicas e Comunicação. São Paulo: Summus, 1996.

BENDER, Arthur. Personal Branding: construindo sua marca pessoal. São Paulo: Integrare Editora, 2009. 
FRANÇA, Fábio. Públicos: como identificá-los em uma nova visão estratégica. São Caetano do Sul: Yendis Editora, 2004.

GUARESCHI, Pedrinho A. (Coord). Comunicação e controle social. Petrópolis: Vozes, 1991.

MALHOTRA, Naresh K. Pesquisa de marketing: uma orientação aplicada. $4^{\mathrm{a}}$ ed. Tradução: Laura Bocco. Porto Alegre: Bookman, 2006.

PRADA, R.R. La opinión pública: análisis estructura y métodos para su estudio. México: Trillas, 1995.

STRAUSS, A. L. Qualitative analysis for social scientists. Cambridge: Cambridge University Press, 1987.

STRAUS, A. L. CORBIN, J. Basic qualitative Research. London: SAGE. 1990:1998.

TUZZO, Simone Antoniaci. Deslumbramento Coletivo: Opinião Pública, mídia e universidade. São Paulo: Annablume, 2005.

Original recebido em: 04/03/2011

Aceito para publicação em: 12/09/11

Resumo sobre os autores

1 Claudomilson Fernandes Braga. Bacharel em Comunicação Social - Relações Públicas pela Universidade Fernando Pessoa. Porto - Portugal. Mestre em Ciências da Religião pela Pontifícia Universidade Católica de Goiás - PUC Goiás. Doutorando em Psicologia pela Pontifícia Universidade Católica de Goiás (PUC Goiás). Professor Assistente da Faculdade de Comunicação (Facomb) da UFG. Coordenador do Centro de Estudos e Pesquisa em Relações Públicas - CEPE da Facomb - UFG.

http://buscatextual.cnpq.br/buscatextual/visualizacv.do?id=K4102466A0

${ }^{2}$ Simone Antoniaci Tuzzo. Bacharel em Comunicação Social - Relações Públicas pela Universidade Metodista de São Paulo. Mestre em Comunicação Social pela Universidade Metodista de São Paulo. Doutora em Comunicação Social pela Universidade Federal do Rio de Janeiro - UFRJ. Professora Adjunta da Faculdade de Comunicação e Biblioteconomia (Facomb) da UFG. Coordenadora da Pós-Graduação Lato Sensu - Assessoria de Comunicação e Marketing e professora efetiva do Programa de Pós-Graduação Stricto Sensu em Comunicação da Facomb - UFG.

http://buscatextual.cnpq.br/buscatextual/visualizacv.do?id=K4707008A6 